\title{
Innovation of hardness tester mechanism and its functionality test
}

\author{
František Bárnik ${ }^{1, *}$, Milan Sága ${ }^{1}$, Ondrej Štalmach ${ }^{1}$ \\ ${ }^{1}$ University of Žilina, Faculty of Mechanical Engineering, Univerzitná 1, 010 26, Žilina, Slovakia
}

\begin{abstract}
The article is focused on constructional design of device mechanism innovation. In the introduction is describe device and his original mechanism. Next section is focused on constructional design of device mechanism innovation and his describe. Another step is comparison between original mechanism and innovated mechanism. In the conclusion are evaluated theoretical and practical benefits of innovation.
\end{abstract}

Keywords: hardness, hardness tester, innovation

\section{Introduction}

Actual engineering practice, which is in the period of automated high-productivity production, is characterized by an increase in quality requirements. Because many factors affect the production process, it is not possible to produce material with ideal properties. The manufactured components exhibit minor or greater deviations from the ideal mechanical properties. Therefore, the function of product reliability and durability is affected not only by the keeping accuracy of the dimensions, the accuracy of the geometric shape and mutual position of the elements of parts, but also keeping the mechanical properties of the material. Constant development of progressive technologies used in mechanical engineering, progress in the design of products and the rapid development of information technology, push manufacturers of measuring technology to constantly upgrade measuring instruments. The aim of the article is to approach the constructional design of device mechanism innovation. The deviace is hardness tester HPO-250 KR/AQ. The hardness tester HPO-250 KR / AQ is a versatile hardness measuring device capable of measuring material hardness by 3 methods: Rockwell, Brinne and Vickers. These are the 3 most commonly used methods of hardness measurement in industry The task was to design constructional changes to the device mechanism so that the device can measure and evaluate the hardness of the material using the computer program by all the hardness measurement methods provided by the device (Rockwell, Brinell, Vickers), without the need for manual exchange of indenters bodies and lenses.

\footnotetext{
* Corresponding author: frantisek.barnik@fstroj.uniza.sk

Reviewers: Wieslawa Piekarska, Jozef Bocko
} 


\section{Hardness tester HPO-250 KR/AQ}

The hardness tester HPO-250 KR/AQ (Fig. 1) is intended for measuring material hardness with the Vickers, Rockwell and partially with the Brinell method using a $\varnothing 2.5 \mathrm{~mm}$ ball. In automatic mode the process of measuring is controlled by PC. The imprint scanning is carried out by a sensitive CCD camera with high resolution, necessary for precise processing of measured results. The camera is connected with PC by BNC cable. The hardness tester HPO$250 \mathrm{KR} / \mathrm{AQ}$ works under Windows 7 operating system. The program of device is a new software for collecting and statistic data evaluation of hardness tester, which works according to the Brinell, Vickers and Rockwell method. This product fully cooperates with the network and enables data export to the server for further processing. The database is also accessible from the network enviroment, so that the measured results are also accessible to another users in case of necessity $[1,2]$.

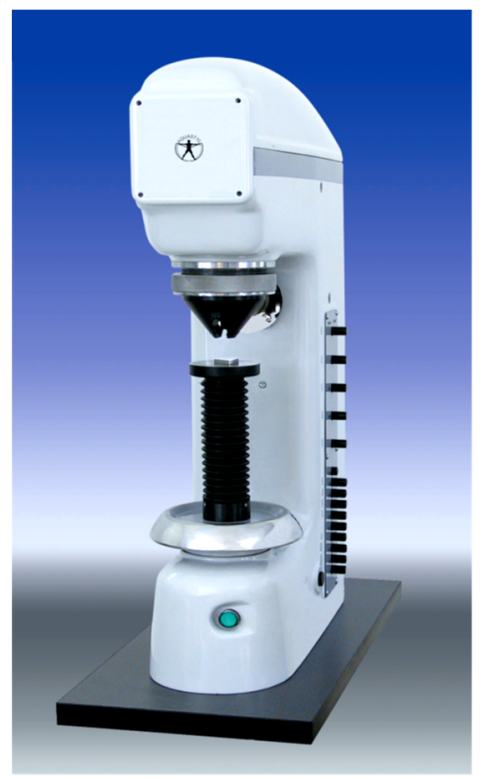

Fig. 1. HPO-250KR/AQ

\subsection{Description of the device mechanism}

The original mechanism of the hardness tester HPO-250 KR / AQ (Fig. 2). The actual assembly of lens and indenter is mounted on the tipping body (3). On this body is fixed punch (4) and vertical illuminator (9). The punch is made so that it was possible to mount indenter (5). It is possible to screw a lens (10) in the vertical illuminator corresponding to the requirements of the relevant measuring methodology. These parts are surrounded by an interrupted retainer that serves to hold the test item (6) on the test table (7). The retainer also protects the indenter and lens from damage. The tipping body is pivotally mounted in a pressure housing (2) which is guided in the guide housing (1). Tilting is provided by the motor that is coupled to the tipping body with the swingarm (8). When the measurement is started, the motor turns the tipping body from the position of the lens to the position with the indenter. Then begins the indentation of indentor into the material according to the relevant methodology. Upon completion, the engine turns the tipping body to the starting position. The imprint is then evaluated using the software. 


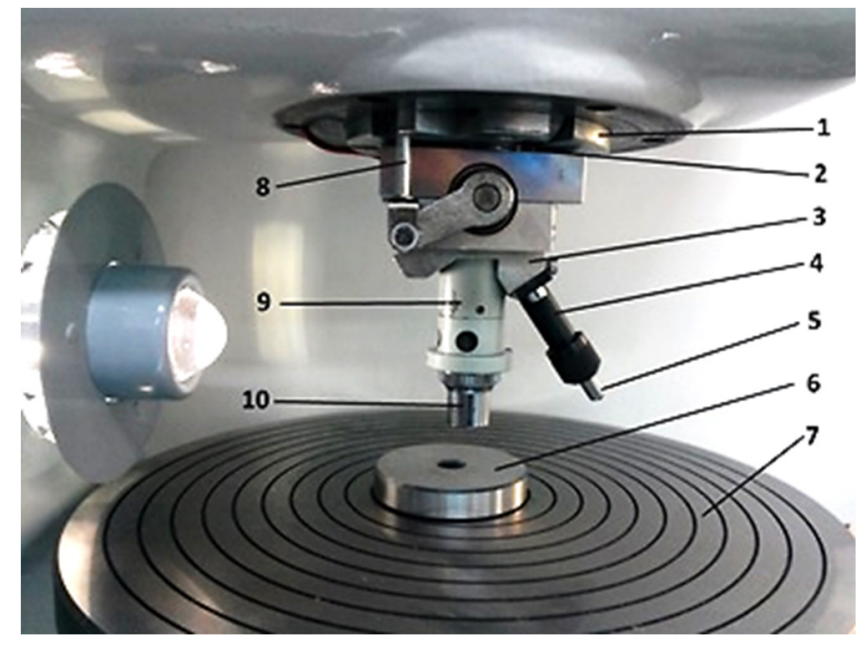

Fig. 2. The original mechanism of the device

In order to perform a hardness measurement, it is necessary to fit in the measuring device a lens that is suitable in the present case and a suitable indenter according to the respective measuring method. This requires manual removal of the retainer, lens, and indenter by service worker. Attachment of the respective lens, indenter and subsequent reassembly of the retainer are followed. Making such exchanges is time-consuming [3].

\section{Constructional design of mechanism innovation}

Some requirements have been made for the design of the hardness tester mechanism innovation. The innovated device have to make a imprint according to the appropriate method (Vickers, Brinell, Rockwell) and then capture it using a CCD camera (Vickers, Brinell) or using a sensor (Rockwell). From a imprint, evaluate the hardness using a computer program and secure archiving in the computer's memory or external memory. The device should be able to carry all the necessary imprints and lenses and, if necessary, enable them to be swiftly exchanged.

The request to innovate the mechanical parts of the hardness measuring instrument was given by one of the managers of AQUASTYL SLOVAKIA s.r.o. The reason was that customer firms demanded the removal of manual change of indenters and lenses by service workers in changing the hardness measurement method. This exchange is very time consuming and reduces the efficiency of measurement. The constructional design of the innovation is a rotary mechanism that is capable of simultaneously carrying 3 lenses and 3 indenters. Rotation the rotary head and precise positioning of indenters and lenses is ensured through the gear wheel that drives the precise stepper motor.

Figure 3 shows a constructional design of mechanism innovation. Designing the mechanism's innovation was complex because the design of innovation was not the whole device but only a part of it. The innovated mechanism had to be adapted to the original concept of the device, which in some cases caused complications. When designing all the components of the mechanism, optimum materials have been prescribed to meet the requirements of the machine. The mechanical part has been carefully designed to ensure high precision and durability of the device. Professional literature $[4,5,9,10]$ was also used in the constructional design of individual components. 


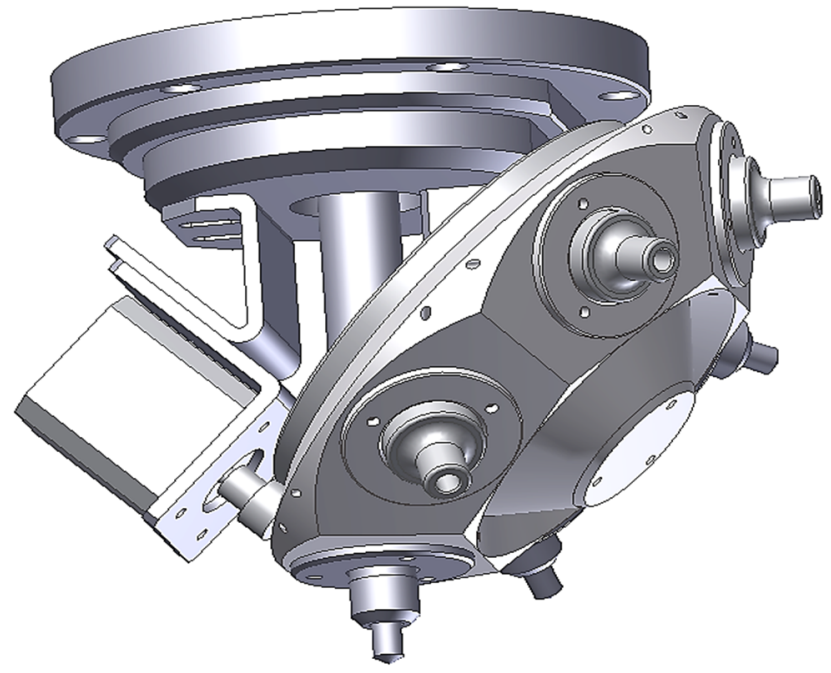

Fig. 3. Model of innovation mechanism

\section{Comparison of mechanisms}

The original device mechanism is capable of simultaneously carrying only one lens and one punch with the indenter. When changing the lens or the indenter, the operator of the device must first dismantle the device retainer and then replace the indenter and the lens. After replacing the indenter or the lens, it is necessary to screw back the retainer.

The innovated mechanism of the device, unlike the original, is capable of carrying 3 lenses and 3 penetrating bodies simultaneously. When changing the hardness measurement method, the appropriate method is selected in hardness tester software. The mechanism automatically sets the punch with the corresponding indenter into the measuring position. When changing the lens, the appropriate lens is selected in the device software as required, and the mechanism of hardness tester automatically sets the selected lens into the evaluation position of device. Since the rotary head is capable of simultaneously carrying 3 penetrating bodies and 3 lenses, the operator's time is no longer required to remove the retainer and then manually replace the indenter or lens. Therefore, the time required for the replacement of the relevant element is substantially shorter, which ultimately results in an increase in the efficiency of the device during the measurement. The comparison between the mechanisms is shown in Table 1.

Table 1. Comparison between the mechanisms

\begin{tabular}{|c|c|c|}
\hline & Original mechanism & Inovated mechanism \\
\hline Number of lenses & 1 & 3 \\
\hline Number of indenters & 1 & 3 \\
\hline Replace the indenter & $\begin{array}{c}\text { manually with the assist of the } \\
\text { operator }\end{array}$ & automatically by selecting the operator \\
\hline Replace the lens & $\begin{array}{c}\text { manually with the assist of the } \\
\text { operator }\end{array}$ & automatically by selecting the operator \\
\hline
\end{tabular}




\section{Tests of functionality and capability of the measurement in- strument}

Function tests on the HPO-250 KR/AQ instrument were performed in an accredited calibration laboratory. All tests were performed under standard conditions. They followed the initial tests of the innovated device mechanism.

The capability of the device has been verified for all 3 relevant methodologies by which the device is capable of evaluating the test material. According to relevant literature $[6,7,8]$, for a capability device, the capability index should be $\mathrm{C}_{\mathrm{gmk}} \geq 1.33$. At least 25 repetitive measurements should be made in the assessment of capability. For each hardness measurement method, 30 measurements were made and the appropriate values were recorded in the tables. From the measured values, the basic statistical characteristics of the process $X_{a}$ and $\mathrm{S}_{\mathrm{w}}$ were calculated for each method. The $\mathrm{C}_{\mathrm{gm}}$ and $\mathrm{C}_{\mathrm{gmk}}$ capability indexes were further calculated (Table 2) to determine the hardness tester capability. According to the established criterion, the lower of the calculated values is always taken into account in determining the capability of the device. The results show that the hardness tester can be considered as suitable by all three methods (Rockwell, Brinell, Vickers). The indexes $\mathrm{C}_{\mathrm{gmkU}}, \mathrm{C}_{\mathrm{gmkL}}$ and $\mathrm{C}_{\mathrm{gmk}}$ have the same value for each of the three methods. The same value was issued because the average calculated value is the same as the value of the respective calibration sample.

Table 2. Table of calculated values of the $\mathrm{C}_{\mathrm{gmk}}$ and $\mathrm{C}_{\mathrm{gm}}$ indexes

\begin{tabular}{|l|c|c|c|}
\hline Measurement method & Index $\boldsymbol{C}_{\boldsymbol{g m k}}$ & Index $\mathbf{C}_{\mathbf{g m}}$ & Capability \\
\hline Rockwell & 1.63 & 1.63 & suitable \\
\hline Brinell & 1.47 & 1.47 & suitable \\
\hline Vickers & 1.97 & 1.97 & suitable \\
\hline
\end{tabular}

For the Rockwell method, the graph of the variations of the measured deviations was constructed from the measured values (Fig. 4). From the measured deviations was calculated the mean deviation $\mu=0.01(0.02 \%$ of the measured value $)$ and the corresponding standard deviation $\mathrm{s}=0.1539(0.31 \%$ of the measured value $)$.

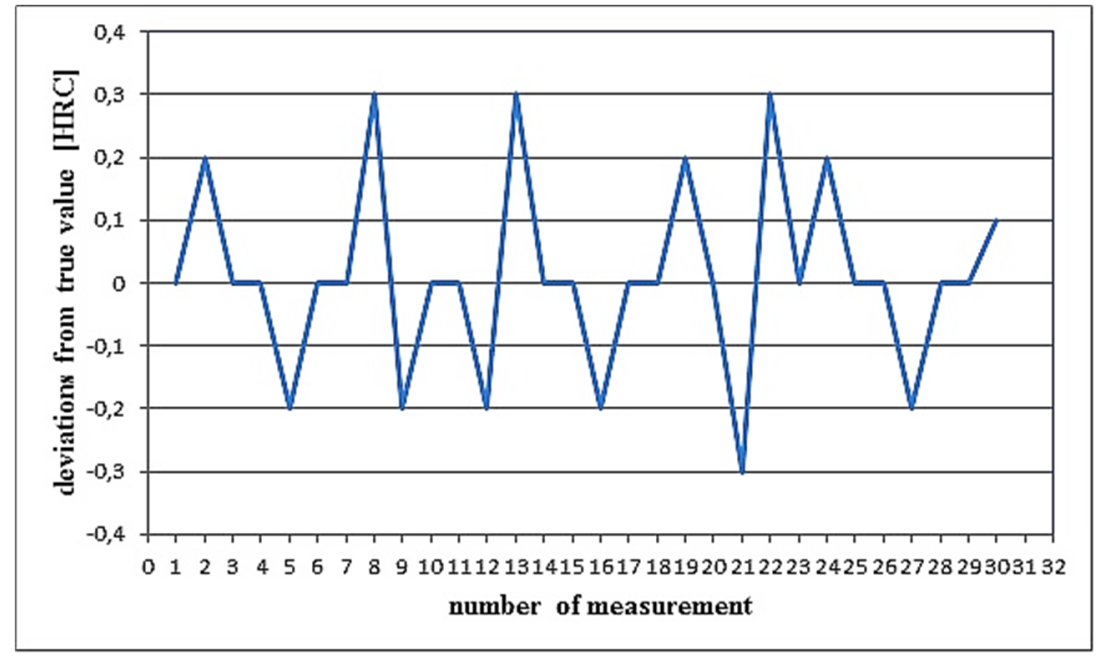

Fig. 4. Graph of measured deviations for the Rockwell method 


\section{Conclusion}

At present, when modern technology puts great demands on the precision, quality and efficiency of the measuring instruments, it is necessary to produce products with the required shapes, dimensions and properties that will meet the highest quality requirements. In production, however, is produced materials whose mechanical properties are not accurate and exhibit certain deviations from the nominal values. The task of measuring instruments is to measure and evaluate deviations that arise during the production of materials and components due to various negative influences.

This article discusses the design of the device mechanism innovation, which is a rotary mechanism. The constructional design was based on the original concept of the device. The proposed mechanism is capable of simultaneously carrying 3 indenters and 3 lenses. The device will allow individual elements to be automatically exchanged using computer software and it will save time for operators. The benefit of the mechanism's innovation is to increase efficiency and save time when measuring, and thus economic benefit. The time required for measurement with exchange the indenter is $65 \%$ less than that of the original mechanism. Therefore, it will be possible to measure the hardness over a much larger number of measured samples at the same time. The upgraded device will therefore greatly benefit companies that need fast, accurate, and efficient hardness evaluation.

This work has been supported by the Slovak Research and Development Agency under the contract No. APVV-14-0096 and KEGA project No. 015ŽU-4/2017.

\section{References}

1. P. Veles, Mechanical properties and testing of materials. Bratislava: ALFA. 408 p. (1989)

2. http://www.aquastyl.sk (cit. 17.05.2018)

3. F. Bárnik, Innovation mechanical parts of hardness tester HPO250 KR/AQ. Diploma thesis. University of Zilina, (2015)

4. S. Černoch, Mechanical engineering manual Volume 1. Prague: SNTL. 1296 p. DT 621, (1977)

5. S. Černoch, Mechanical engineering manual Volume 2. Prague: SNTL. 2586 p. DT 6217, (1977)

6. M. Dovica, et al., Metrology in mechanical engineering Kosice:EMILENA, 351p (2006)

7. M. Ťavodová, Assessment of measurement instrument capability. (2006) http://www.tuzvo.sk/files/FEVT/fakulta_fevt/tavodova.pdf (cit. 11.04.2015)

8. A. Sapietová, V. Dekýš, M. Sapieta, P. Pecháč, Application of computational and design approaches to improve carrier stability. Procedia Eng. 96, 410-418 (2014)

9. B. Leitner, M. Vaško, Design and Modelling of Tank Wagon Assembly Operations in CAM Environment. Transport Means 2015 I \& II, 87-90 (2015)

10. P. Kopas, L. Jakubovičová, M. Vaško, M. Handrik, Fatigue Resistance of Reinforcing Steel Bars. Procedia Engineering 136, 193-197 (2016) 